\title{
After the crisis, a new European governance
}

\author{
Pier Carlo Padoan ${ }^{1}$
}

Published online: 30 October 2015

(C) Springer International Publishing Switzerland 2015

\section{The state of the economy in Europe}

The depth of the economic and financial crisis, and its lasting impact, as well as the evolution of the Greek crisis highlight still unsettled issues and weaknesses, linked in part to the incompleteness of the Economic and Monetary Union, notwithstanding the establishment of the European Stability Mechanism, Banking Union, and the strengthening of budgetary surveillance.

The overall economic performance of the Euro area remains disappointing, with persistent low growth rates and high unemployment. The impact of the crisis on growth potential, largely due to the drastic reduction in investment and the deterioration of human capital, could persists for a long time... No wonder that the risk of a secular stagnation has been evoked.

The recovery that has been developing over the past several quarters is encouraging but modest. To obtain stronger and more sustained growth and job creation, decisive policy action is needed beyond the current policy mix and the positive contribution by the ECB policy stance. Action must be accelerated on several fronts: structural reforms, investment, and deeper economic integration. If on the contrary, complacency were to slow down efforts to boost growth, visible progress in growth and job creation would fail to materialize. In such a case, as EU citizens are still heavily affected by the legacy of the crisis, in terms of

This focus is the speech delivered at Accademia Nazionale dei Lincei, Rome, on the 6th of May 2015 by Pier Carlo Padoan, the Italian Minister of Economy and Finance. The Editor in Chief thanks Prof. Pier Carlo Padoan and Accademia Nazionale dei Lincei for giving permission to publish it.

Pier Carlo Padoan

segreteria.ministro@tesoro.it

$1 \quad$ Ministry of Economy and Finance, Rome, Italy 
unemployment, poverty, and growing inequalities, the disaffection towards the European project would become more widespread than what already seen, boosting consensus for populist perspectives.

The European Union and the euro area in particular stand at a crossroads between muddling through an hesitant recovery or tackling the challenges of restoring growth potential, fostering employment within a stable macroeconomic environment, and rebuilding trust between the European institutions and European citizens. The Greek crisis and the possibility that exiting the euro would become a serious option has increased the risk that monetary union could become revertible and eventually unfold. To avoid such a scenario we need a stronger policy mix, more effective economic governance, a consistent institutional architecture for the euro area and a stronger effort towards integration in the EU as a whole. We must proceed, along, but go beyond, the lines recommended by The Four Presidents' Report "Towards a genuine Economic and Monetary Union", keeping in mind that a first set of measures can be implemented within the existing EU Treaty, while more far-reaching measures might require changes to the Treaty.

\section{The policy mix in the $\mathrm{EU}$}

The current policy mix in the EU is moving in the right direction. The ECB's QE, is having a positive impact on interest rates and financial markets. The weakening of the euro should also be seen as an indirect consequence of QE. It is important to note that the move towards a more proactive monetary policy stance in the Eurozone has been facilitated, in its rationale and in its impact, also by the implementation of responsible fiscal policies and national reform programs in the EU Member States,. QE also helps create more favorable conditions for the implementation of structural reform measures in Member States as reforms deliver better results in an expanding economy. However QE will have only limited impact if not supported by other policies.At the same time, interest rates hovering around the zero threshold for too long might have negative effects in the medium term, setting the stage for potential bubbles in financial markets and real estate. In short QE cannot be expected to last forever and with an unchanged impact.

The fiscal stance in the EU is close to neutral and acting much less than in the past as a drag on growth. The Commission's Communication on flexibility, in January 2015, has provided incentives to Member States to introduce and implement structural reform measures, through the structural reform clause. Overall such a policy environment, boosted also by a cheaper price of oil, provides a window of opportunity that must be exploited without delay and hesitation.

Recovery of investment is crucial to put the EU back on a path of sustainable growth. Investment, supports demand in the short-term, and strengthens supply and potential output in the medium-term. Over the recent past, the fall in investment in the European countries has been dramatic and widespread, amounting to 370 Billion Euros compared to the pre-crisis level. In Italy, in 2014 alone, investment has decreased by 3.3 percent. To help reverse this trend, also thanks to the efforts of the Italian Presidency of the Council of the EU in putting investment and growth back 
on the agenda, the Commission has launched the Junker Plan and created the European Fund for Strategic Investment (EFSI). The Plan is an important opportunity to boost private investment with public support, that would bear the additional risk private companies are not be prepared to take on,.

But more needs to be done to support growth. Further strengthening the internal market is a priority and an opportunity that needs to be much better exploited: there is ample scope for additional benefits, through deeper integration, and stronger competitiveness of the European economy. The single market has been at the heart of the European growth strategy for more than two decades, however, national interests, institutional barriers and bottlenecks, both at national and at EU level, have prevented to reap the full benefits in terms of competitiveness and growth. The ongoing efforts to revitalize the single market, targeted at removing obstacles to the single capital market and creating a Capital Markets Union, overcoming the segmentation of the energy market, and promoting the digital economy and innovation go in the right direction. Beyond this we should keep in mind that the ultimate source of growth in an ageing economy such as the EU is through innovation driven productivity. In this respect the goal should be to move towards a full fledged Innovation Union i.e. the EU should adopt an integrated set of initiatives, to stimulate knowledge creation through education and research, which are the main drivers of innovation.

Short of this the question remains whether the policy mix is sufficient to ensure that the current economic recovery is stronger and more sustained than a limited, cyclical episode, and hopefully will be ushering a prolonged period of growth.

Supply-side policies (structural reforms) must be coordinated more effectively with fiscal policy, as recognized in the EU Commission's Communication on flexibility. Strong structural action will boost medium term growth thus supporting consolidation of public finance that will, in turn, strengthen economic growth. Better and more targeted use of fiscal space, in both spending and taxing decisions will reinforce the impact of structural measures. All EU countries need to implement structural reforms, not only periphery countries. The more so euro area members that need to compensate the loss of an independent monetary policy with more flexibility and resilience in labour and product markets. Countries with current account surplus should take measures to reduce them, preferably though more investment, as shown by the EU Commission's Report on macroeconomic imbalances. Structural reforms would support also a major rebalancing as they open profit opportunities that stimulate investment. In this respect accommodative monetary policy would enhance the impact of structural reforms by maintaining favorable financing conditions

As for the Juncker Investment Plan to be effective the following aspects should be kept in mind. First, the implementation of the Plan must be swift, although it is now clear that first effects will begin to be seen in some time in 2016. The second issue concerns the effective additionality effect of public resources. It is essential that the new Fund (EFSI) finances projects that are additional with respect to investment already planned in current European programs. The Plan should activate projects which would not otherwise materialize, due to excessive risk, market failures, or financial and budgetary constraints. The identification of high quality 
projects is one of the crucial issues for the success of the Plan. Moreover, for some projects, the leverage effect could be lower than expected. One question to be clarified is the consistency between state aid regulations and Fund prospective operations. Last but not least the success of the Plan depends also on the contributions from national development banks, some of which have committed to supporting projects and platforms in the framework of the Plan.

A Capital Markets Union is a welcome initiative. The capital market in the EU is relatively less developed compared with the U.S.A. In the EU business environment funding is dominated by the banking system, and it is largely organized along national lines. Deeper and more accessible capital markets could contribute to boost investment, growth and jobs. To become effective in a long-term perspective, the EU single capital market requires greater convergence in corporate and bankruptcy regulatory regimes, as well as in tax law systems within the EU.

Much remains to be done in energy and labor markets. With regard to energy, the integration of national markets, would have a significant impact on the competitiveness of the European economy, Harmonization of national regulations of the labor market would encourage labor mobility and would be enhanced by the pooling of resources to support adjustment and reallocation. A common unemployment scheme would increase the resilience of the Union (and more importantly the euro area) and facilitate macroeconomic stabilization. Furthermore, the portability of individual pensions would help pooling national pension funds at European level, that could boost long term investment projects at EU level.

\section{Changing governance}

To boost the performance of monetary union changes in governance are also needed. A monetary union is dynamically unstable if structural differences persist among member countries. EMU cannot survive in the long term unless it continues to move forward in terms of integration, ultimately leading to a political union. We cannot stay still. If we do we risk a return to the vicious circle of "fragmentationshort-term vision-further fragmentation" that we have seen at work in the years of crisis, 2011 and 2012; we must instead put in place a virtuous circle of "integrationlong-term strategies- more integration." To obtain such a change in direction the current policy mix must be strengthened along the lines discussed above; however, we also need significant changes in the governance and functioning of the Union.

To make monetary union really irreversible a change of mind is required: we must manage our European common house, not only on the basis of national interests, but by adopting a, systemic, common approach. Awareness of the systemic nature of problems in monetary union has been largely insufficient during the crisis, leaving the burden of adjustment largely, if not exclusively on individual countries measures based on the principle of internal devaluation. This approach is insufficient. The financial crisis, has highlighted the need to reform European governance along the lines of greater symmetry in adjustment, on the one hand, and more flexibility, and confidence on the other. We need more symmetric adjustment pressure between debtors and creditors, drawing on the G20 approach for the 
correction of global imbalances. The stigma attached to debtors who fail to restore orderly market conditions, has led to a dramatic impact on aggregate demand in the Eurozone. We should never forget that for each reckless borrower there is also an unwise lender. The implication is that countries with current account surplus should contribute to the adjustment, increasing the level of investment. In this light, we need to strengthen incentives for those countries to adopt expansionary policies, in the context of the EU Commission's Country Specific Recommendations. To make symmetry effective more needs to be done to avoid both reckless lending and reckless borrowing, i.e. avoiding moral hazard, At the same time risk sharing must make more progress to strengthen monetary union. In other words, the responsibilities of individual countries must be integrated with the collective responsibilities of the system as a single, unified body.

This approach can be applied to a variety of policy dimensions. Much has been done with the peer-review of national budgets at the Eurogroup level, within the European Semester and the recently introduced Draft Budgetary Plan procedure. Nevertheless, more progress remains to be achieved for the definition of a coherent policy strategy, which considers, in a more systemic and explicit way, the supranational dimension and the implications for each country. We need to establish a much closer link between the analysis and policy recommendations at the aggregate level and their implications for individual countries, taking into account, much more than is the case now, the spillover effects of national economic policies on other countries.

The flexibility Communication promotes the national adoption of structural reforms, which are necessary to increase growth potential. To complement the national effort a European mechanism to support cyclical unemployment would enhance labor market adjustments, reinforcing the positive effects of national reforms and their effectiveness. It would help consolidate medium term growth by smoothing downturns and preventing or limiting hysteresis. It would be a further sign of the irreversibility of the Euro, with a positive impact on expectations.

More generally the development of a stabilization function to cope with asymmetric shocks implies an increasing degree of integration and fiscal transfers financed by a common fiscal capacity. These mechanisms, which are part of well functioning monetary unions, would give countries a chance to smooth out the adjustment needed in presence of negative shocks, avoiding, altogether, overly restrictive adjustment policies. From this perspective, moves towards a Fiscal Union would require a further transfer of sovereignty, taking a step towards a genuine Political Union.

Fiscal Union might be shaped in different ways, ranging from a common budget to the introduction of Eurobonds regarding which many proposals have been put forward, with different characteristics and scope. However, some types of Eurobonds and, all the more so, a real fiscal union would require changes to the EU Treaty.

The creation of the Banking Union, a great achievement in the process of institutional innovation launched by the EU, has led to the establishment of the Single Resolution Fund (SRF), a key instrument for mutualization of resources. However, two elements to complete the construction of an efficient Banking Union 
are still missing: a single deposit guarantee scheme, and the implementation of the agreement on the establishment of a common public support (the so-called Backstop) for the SRF.

The completion of the Banking Union should go hand in hand with the establishment of a genuine single capital market, a Capital Markets Union. This would also introduce a further element of risk sharing through the development of financial markets and the related insurance mechanisms.

Last but not least the institution of the European Stability Mechanism (ESM) has been a major advance for the management of sovereign risk, through the use of pooled resources. An ambitious goal, to be achieved in the medium term, would be transforming the ESM into a genuine European Monetary Fund. This is certainly one of the lessons to be drawn from the Greek crisis.

\section{Conclusions}

A lesson arising from the financial crisis, is that the stability and progress of economic and monetary union requires more mutual trust, and greater attention to the positive externalities of the integration process. Mutual trust can be accumulated by showing peers that one country abides by the rules. Rules must be designed so as to reward good individual behavior and discourage uncooperative behavior (i.e. prevent moral hazard). Rules must be designed also to provide risk sharing mechanisms that are a key component of well functioning monetary and economic unions. In other words rules must allow for mutualization. The two elements are mutually reinforcing. Preventing moral hazard strengthens mutual trust and supports mutualisation. Risk sharing and mutualisation offer a powerful incentive to abide by the rules and prevent opportunistic behaviour.

To summarize progress towards a genuine monetary union requires pooling resources and developing common institutions, following the examples of ECB and the Banking Union. This, in turn, requires mutual trust among the partners. Crises are detrimental (also) because they destroy trust, i.e. the very fabric of a monetary union. To strengthen monetary union we need to replace the vicious circle "mistrust-fragmentation", which dominated during the crisis, with the virtuous sequence "confidence-mutualization". EMU was conceived from the very beginning as a means to build confidence, helping overcome the distrust historically rooted among European countries. Rebuilding trust among Member States, and between them and the EU Commission, on the one hand, and defusing national prejudices, on the other, are the principles that should guide the actions of European governments in our effort to learn from the crisis. 